J. Clin. Chem. Clin. Biochem.

Vol. 28, 1990, pp. 919-921

(C) 1990 Walter de Gruyter \& Co. Berlin $\cdot$ New York

\title{
CA 19-9 and CA 125 Determination by Immunoluminometric Assay
}

\author{
By M. Plebani, D. Faggian, M. Masiero, Alda Giacomini and A. Burlina \\ Cattedra e Servizio di Biochimica Clinica, Università di Padova and Centro di Ricerca Biomedica, Castelfranco \\ Veneto (TV), Italia
}

(Received March 3/July 27, 1990)

Summary: We evaluated a new immunoluminometric technique (ILMA) for the measurement of the cancer antigens, CA 19-9 and CA 125 in serum. A satisfactory reproducibility was found, coefficients of variation ranging from 4.2 to $7.3 \%$ in within-run and between-run assays. The linearity of tests was maintained over a wide concentration range. Mean analytical recovery was $94 \%$ for CA $19-9$ and $98 \%$ for CA 125 . A significant agreement between results obtained by immunoradiometric assays and evaluated methods was found both for CA $125($ ILMA $=0.917$ IRMA + 1.048; $\mathrm{r}=0.966 ; \mathrm{n}=98)$ and CA 19-9 (ILMA = 1.156 IRMA + 0.996; $\mathrm{r}=0.995 ; \mathrm{n}=100)$.

\section{Introduction}

Cancer antigens (CA) $19-9$ and 125 are tumour-associated antigens, which can be detected by monoclonal antibodies. The clinical value of serum CA 199 as a tumour marker of gastrointestinal carcinomas, and that of CA 125 in ovarian carcinomas has been proved $(1,2)$.

Until now CA 125 and CA 19-9 have been measured by immunoradiometric assays (IRMA). All these assays suffered the well-known disadvantages of ${ }^{125} \mathrm{I}-$ labelled tracers: contact with radioactive material and short-life of the tracer, and its instability due to radiolytic damage to the labelled protein.

The aim of the present work was:

a) to evaluate the analytical efficiency of a new immunoluminometric (ILMA) technique for the determinations of CA 19-9 and CA 125 in serum;

b) to compare the results obtained in cancer patients by IRMA and ILMA methods.

\section{Materials and Methods}

A total of 200 subjects were included in this study: 32 were control subjects ( 21 males, eleven females, aged 19-59 years).
Twenty-eight patients were affected by pancreatic cancer of duct cell origin ( 20 males, eight females, aged $43-71$ years). Twenty six had chronic pancreatitis $(23$ males, three females, aged 29-65 years). The diagnosis was based on the clinical picture and on the positive results of at least two of the following examinations: plain abdomen x-ray for pancreatic calcification, pancreatic ultrasonography, endoscopic retrograde pancreatography, computerized axial tomography. Thirty-seven (27 males, ten females, aged 31-68 years) presented extra-pancreatic diseases diagnosed on the results of specific radiological and/or histological procedures. Thirty-four patients had an ovarian carcinoma confirmed histologically (27 serous, seven undifferentiated).

The other 43 patients were affected by ovarian benign pathology (27 serous cystoadenomas, five mucinous cystoadenomas, six benign cystic teratomas, five endometriotic cysts).

The new immunoluminometric assays (LIA-mat, reagents by Byk-Sangtec, Milan) employed the original antibodies used in the radioisotopic assays. The OC 125 antibody was obtained by Bast et al. $(3,4)$ by immunization of mice with a cell line derived from an epithelial ovarian carcinoma; the OC 19-9 was produced by Koprowski et al. by immunization of Balb/c mice with a cell line derived from a colorectal tumour $(5,6)$. The same respective antibodies were used for the coating of the inner surface of polystyrene tubes, and (after labelling with the isoluminol derivative, amino-butyl isoluminol (ABEI)) as the luminescent tracer. The luminescence reaction is initiated by addition of alkaline hydrogen peroxide and microperoxidase MP 11, resulting in the burstlike emission of light $\left(\lambda_{\max }=425\right.$ nm) within a few seconds.

The light signal is directly proportional to the concentration of tumour markers in standards or samples. The light-producing reaction and the light-measuring procedure are fully automated 
(Berthold Auto CliniLumat LB952, D-7547 Wildbad, F. R. Germany). The precision studies were performed on patient sera with different concentration (low and high) of cancer antigens. The dilution test was carried out by diluting sera of patients with high concentration of the antigen with the original diluent.

For comparison studies CA 125 and CA 19-9 were determined by two immunoradiometric assays (IRMA A, reagents by Centocor INC, Malvern, USA which employs a bead as a solid phase; IRMA B, reagents by Byk-Sangtec, Milan, which employs the same antibodies on a coated tube). The correlation between different methods for CA 19-9 determination was investigated in 100 subjects (28 pancreatic cancer, 26 chronic pancreatitis, 30 extra-pancreatic diseases and 16 controls). For CA 125 the agreement between different methods was evaluated in 98 subjects ( 43 ovarian benign pathology, 34 ovarian carcinoma and 21 controls)

Statistical analysis of data was performed by regression analysis; precision profiles were calculated according to Ekins (7).

\section{Results}

The reproducibility of the ILMA methods was evaluated both in within-run and between-run assays. Within-run CVs $(\mathrm{n}=20)$ were $5.9 \%$ at $29.3 \times 10^{3}$ $\mathrm{U} / 1$ and $4.2 \%$ at $110.4 \times 10^{3} \mathrm{U} / 1$ for CA $19-9$; and $6.8 \%$ at $16.7 \times 10^{3} \mathrm{U} / 1$ and $4.6 \%$ at $272 \times 10^{3} \mathrm{U} / 1$ for CA 125. Between-run CVs $(n=11)$ were $6.2 \%$ at $29.7 \times 10^{3} \mathrm{U} / 1$ and $5.1 \%$ at $112.1 \times 10^{3} \mathrm{U} / 1$ for $\mathrm{CA}$ $19-9$; and $7.3 \%$ at $15.4 \times 10^{3} \mathrm{U} / 1$ and $5.1 \%$ at 264.1 $\times 10^{3} \mathrm{U} / 1$ for CA 125 .

The precision profile calculated according to Ekins demonstrated the wide range of measurement of this technique (figs. 1 and 2).

Samples were spiked with the antigens and quantitated in order to calculate the analytical recovery. Mean analytical recovery was $94 \%$ (range: $91-$ $102 \%$ ) for CA $19-9$ and $98 \%$ (range: $96-104 \%$ ) for CA 125. The dilutions of sera with high values of $\mathrm{CA}$ 19-9 and CA 125 demonstrated that the LIA-mat technique gives a linear calibration over a wide range of concentrations (up to $4.5 \times 10^{3} \mathrm{U} / \mathrm{l}$ for CA 125 and up to $7.3 \times 10^{3} \mathrm{U} / 1$ for CA 19-9).

Accuracy was assessed by correlation studies.

CA 125: results were significantly correlated with those obtained by IRMA A (fig. 3). A significant correlation was also found between ILMA and IRMA $\mathrm{B}$ results $\left(\mathrm{ILMA}=1.13 \mathrm{IRMA} \mathrm{B}+2.057 \times 10^{3} \mathrm{U} / \mathrm{l}\right.$; $\left.\mathrm{S}_{\mathrm{yx}}=62 ; \mathrm{r}=0.981, \mathrm{p}<0.001 ; \mathrm{n}=98\right)$.

CA 19-9: a significant correlation between the results obtained by IRMA A and ILMA was observed (fig. 4), but a positive bias of the ILMA method was present. However from a clinical point of view, the diagnostic accuracy (tab. 1) of ILMA was not significantly different from that of the IRMA method when the same cut-off level $\left(37 \times 10^{3} \mathrm{U} / \mathrm{l}\right)$ was adopted $(8)$.

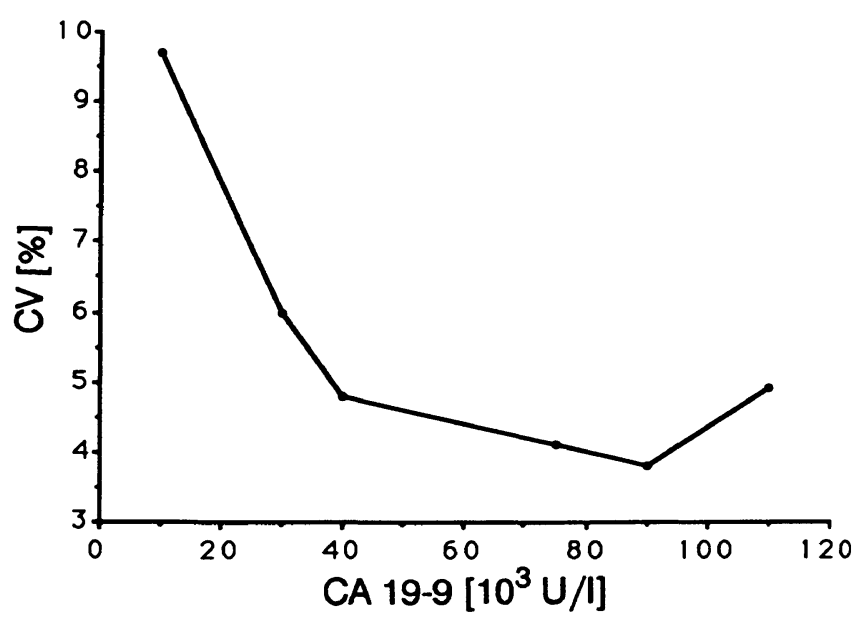

Fig. 1. Precision profile of the ILMA assay for CA 19-9 determination.

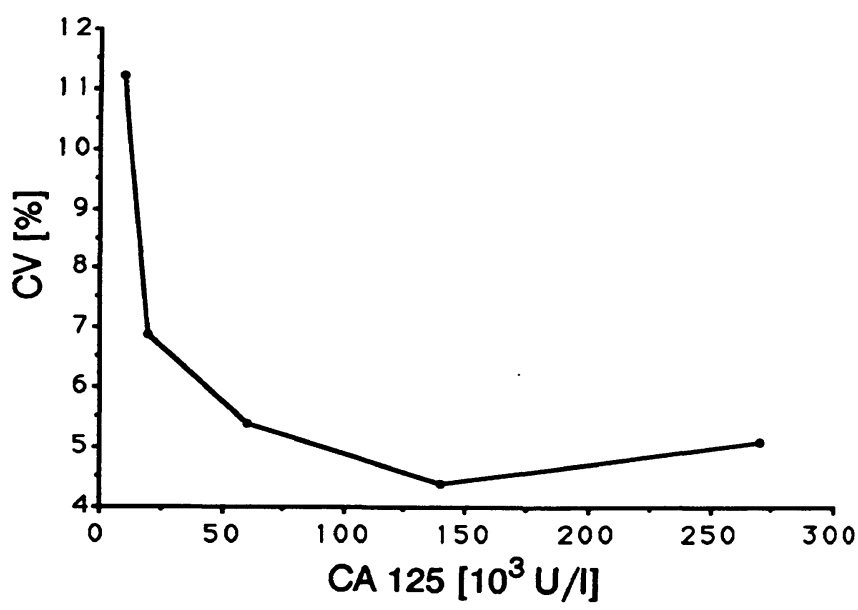

Fig. 2. Precision profile of the ILMA assay for CA 125 determination.

Good agreement was also found between ILMA and IRMA B results (ILMA $=1.056$ IRMA B +1.783 $\left.\times 10^{3} \mathrm{U} / 1 ; \mathrm{S}_{\mathrm{yx}}=55 ; \mathrm{r}=0.963, \mathrm{p}<0.001 ; \mathrm{n}=100\right)$.

\section{Discussion}

Luminescent labels have proved to be efficient in term of both specificity and sensitivity and are therefore suitable for replacing radioisotopes as labels.

Tab. 1. Sensitivity, specificity and diagnostic accuracy of CA 19-9 determination by IRMA and ILMA

\begin{tabular}{lll}
\hline & IRMA & ILMA \\
\hline Sensitivity (\%) & 75.0 & 76.0 \\
Specificity (\%) & 93.7 & 93.0 \\
Accuracy (Y) (\%) & 68.7 & 69.0 \\
\hline
\end{tabular}

Sensitivity $=$ true positive rate; specificity $=$ true negative rate; $\mathrm{Y}=$ Youden index $=100-$ (false positive rate + false negative rate) 


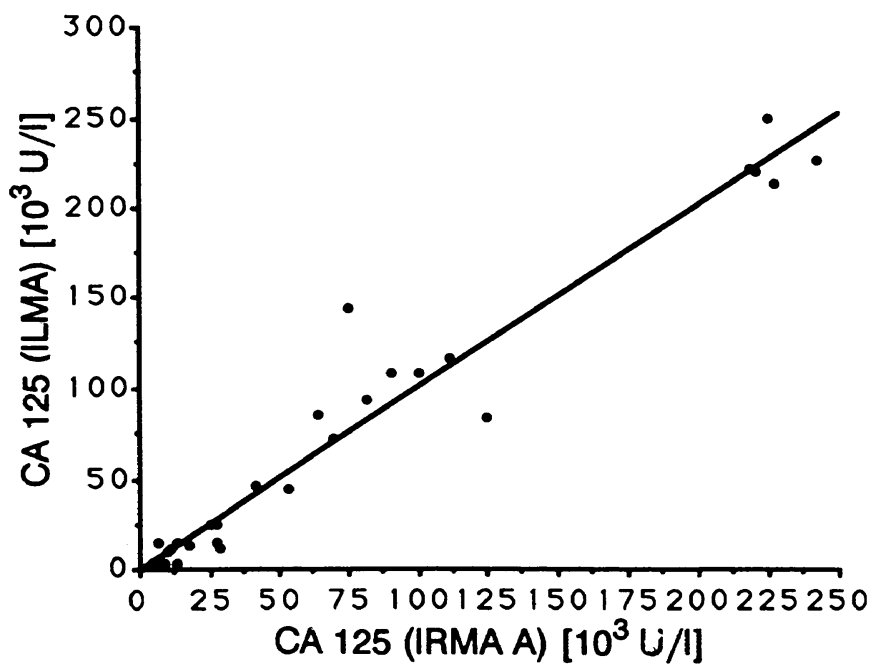

Fig. 3. CA 125: Correlation between ILMA and IRMA A assays $\left(\mathrm{ILMA}=0.917\right.$ IRMA $+1.048 \times 10^{3} \mathrm{U} / \mathrm{l} ; \mathrm{S}_{\mathrm{yx}}$ $=25.0 ; \mathrm{r}=0.966 ; \mathrm{n}=98)$.

The evaluated methods demonstrated good reproducibility both in within and between-run assays. Good analytical recovery and linearity were also observed.

The comparison between the evaluated methods and immunoradiometric assays demonstrated a significant correlation. Moreover, good agreement between

\section{References}

1. Del Villano, B. C., Brennan, S., Brock, P., Bucher, C., Liu, V., McClure, M., Rake, B., Space, S., Westrick, B., Schoemaker, H. \& Zurawski, V. R. Jr. (1983) Radioimmunometric assay for a monoclonal antibody defined tumor marker, CA 19-9. Clin. Chem. 29, 549-552.

2. Davis, A. M., Zurawski, V. R. Jr., Bast, R. C. Jr. \& Klug, T. L. (1986) Characterization of the CA 125 antigen associated with human epithelial ovarian carcinomas. Cancer Research. 46, 6143-6148.

3. Bast, R. C., Feeney, M., Lazarus, H., Nadler, L. M., Colvin, R. B. \& Knapp, R. C. (1981) Reactivity of a monoclonal antibody with human ovarian carcinoma. J. Clin. Invest. 68 , 1331.

4. Bast, R. C., Klug, T. L., St. John, E., Lenison, E., Niloff, J. M., Lazarus, H., Berkoiwitz, R. S., Leavilt, T., Griffiths, T., Parker, L., Zurawski, V. R. Jr. \& Knapp, R. C. (1983) A radioimmunoassay using a monoclonal antibody to monitor the course of epithelial ovarian cancer. New Engl J. Med. $309,883-887$.

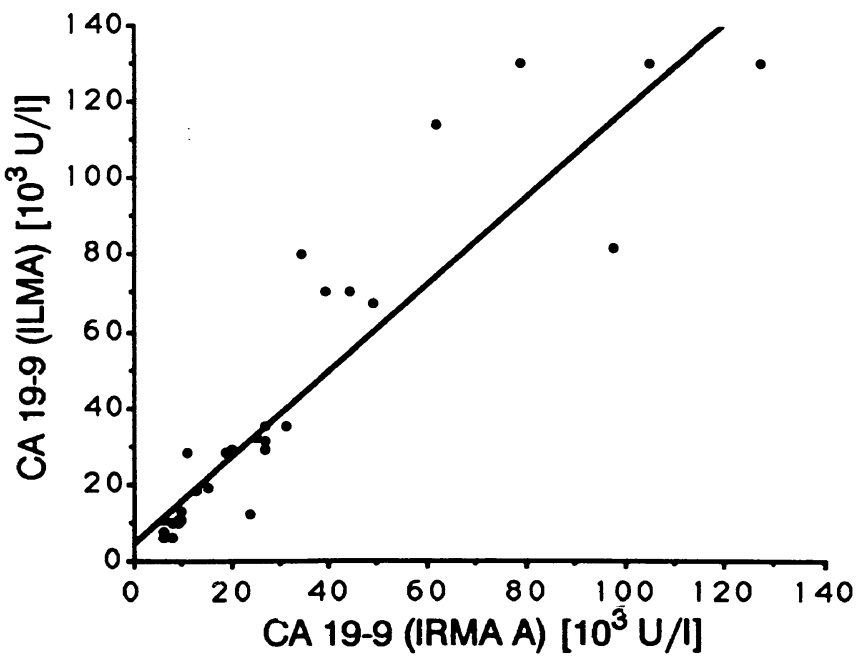

Fig. 4. CA 19-9: Correlation between ILMA and IRMA A assays $\left(\mathrm{ILMA}=1.156 \mathrm{IRMA}+0.996 \times 10^{3} \mathrm{U} / 1 ; \mathrm{S}_{\mathrm{yx}}\right.$ $=27.2 ; \mathrm{r}=0.995 ; \mathrm{n}=100)$.

IRMA and ILMA results was also found from a clinical point of view.

In conclusion, the evaluated technique seems to be precise, accurate, well correlated with IRMA and therefore suitable for routine determination of tumour markers in clinical practice.

5. Herlyn, H., Steplewski, Z., Herlyn, D. \& Koprowski, H (1979) Colorectal carcinoma-specific antigen: Detection by means of monoclonal antibodies. Proc. Natl. Acad. Sci. U.S. A. $76,1438$.

6. Koprowski, H., Herlyn, H., Steplewski, Z. \& Sears, H. F. (1981) Specific antigen in serum of patients with colon carcinoma. Science 212, 53.

7. Ekins, R. P. (1983) The "precision profile": its use in assay design, assessment and quality control, In: Immunoassay for clinical chemistry, 2th edn. (Hunter, W. M. \& Corrie, J. E. T., eds.) pp. 76-104, Churchill Livingstone, Edinburgh.

8. Fabris, C., Del Favero, G., Basso, D., Piccoli, A., Meggiato, T., Angonese, C., Plebani, M., Burlina, A. \& Naccarato, R. (1988) Serum markers and clinical data in diagnosing pancreatic cancer: a contrastive approach. Am. J. Gastroenterol. $83,549$.

Dr. Mario Plebani

Cattedra e Servizio di Biochimica Clinica

Laboratorio Centrale

Via Giustiniani, 2

I-35128 Padova 


$$
\text { . }
$$

